\title{
Exergy as a Parameter for Building Energy Assessment
}

\author{
Lorenzo Leoncini ${ }^{1}$ and Marta Giulia Baldi ${ }^{2}$ \\ 1. Department of Industrial Engineering, University of Florence, Florence 50139, Italy \\ 2.Department of Civil and Environmental Engineering, University of Florence, Florence 50139, Italy
}

\begin{abstract}
The energy and environmental impacts resulting from the buildings sector are one of the impending problems which address the international action. The main strategies implemented to answer to this problem are the energy efficiency improvement, the $\mathrm{CO}_{2}$ emissions reduction and the renewable energy share increase in the energy mix. The key subject discussed in this paper is the "building energy impact", aimed to leading the building sector towards the energy efficiency improvement. The paper's aim is to show that an energy assessment is not able to give a consistent evaluation of building energy use, and it could be misleading. Therefore, the paper proposes the exergy assessment as complementary evaluation method, in order to achieve a complete description of the concept "building's energy impact on the environment". In the first section, we describe the parameters currently used for the building energy assessment, focusing on the primary energy index and the $\mathrm{CO}_{2}$ emissions index. In the second section, we introduce the exergy as a complementary index. This index is a possible answer to the problems previously identified. Finally, in the third section, we present three test-cases, analyzed through transient simulation software TRNSYS. The purpose of the test-cases analysis is to show the difference between energy and exergy assessment.
\end{abstract}

Key words: Building energy assessment, energy performance, exergy performance, indices.

\section{Introduction}

The international action is currently addressed to the primary energy sources consumption, to the climate change and to the natural resources depletion. This awareness has led to a particular commitment to energy and environmental low impact strategies, e.g., reduction of energy needs in residential and services sector, reduction of greenhouse gas emission in transport sector, management of land-use and materials recycling.

In Europe, the residential and services buildings are responsible for $40 \%$ of the total energy consumption. Moreover, they have a relevant impact on the greenhouse gas emissions [1,2]. The buildings energy needs are mainly due to heating and cooling systems. Technological developments in these systems will lead to the energy waste reduction and so to the energy efficiency improvement [3]. The existing buildings stock is energy-intensive and has a low rate of

Corresponding author: Lorenzo Leoncini, Ph.D., engineer, research fields: building energy efficiency and exergy analysis. E-mail: lorenzo.leoncini@unifi.it. renovation. However, the energy saving technologies are more easily implementable in new buildings rather than in existing buildings.

Nowadays, a reduction of the buildings energy needs is required, especially through a rational use of the energy sources. So the guide-lines for existing buildings renovation should be based on the energy saving technologies and on an appropriate use of the energy carriers. The building design should take in account the energy and environmental problems through effective building assessment methods and parameters.

Although the term "sustainable development" is largely applied to economical, social and environmental areas, there is still a need to develop simple assessment methods, especially to evaluate the quality of sustainable buildings [4]. International studies show that the fossil energy sources are limited and the climate change has anthropic origin [5].

The European Union's answer to the energy and environmental issue is the reduction of primary energy consumption and greenhouse gas emissions through a 
double strategy: the energy efficiency improvement and the renewable energy share increase in the energy mix $[1,2]$. The economical aims of these strategies are to avoid payment of penalties on greenhouse gas emissions and to reduce the exposure to international energy prices. This strategy has led to the current regulatory framework, which meets the mentioned aims. However, a consistent definition of the concept "building's energy impact on environment" is still lacking.

The paper briefly reviews the current buildings assessment parameter and proposes the exergy as a complementary parameter.

\section{Building Energy Assessment}

\subsection{Energy Efficiency}

We believe that to build or to renovate a low impact building means to minimize its "energy impact on the environment". This concept only refers to the building energy features. The building interaction with the surrounding environment and with the energy supply chain, which leads to an energy consumption and to a greenhouse gas emissions, implies its non-neutrality on the environment.

A building uses energy throughout its life, i.e., from its construction to its demolition. The building energy needs during its life cycle are both direct and indirect. The direct energy needs are for construction, operation and demolition. Instead, the indirect energy needs are for the materials production and disposal $[6,7]$. The assessment method proposed in this paper does not consider all interactions between the building and the other natural resources such as soil, water, air, etc.. Also, it does not take into account the transitional stage of building construction and demolition, and the related impacts. A building requires energy during its operating stage and so it has a double impact on the environment: the first due to the energy consumption; the second due to the greenhouse gas emissions.

The European Union answers to the question of "efficiency" in the building sector by defining the "energy performance", expressed by a primary energy index or a $\mathrm{CO}_{2}$ emissions index [8]. So in the current regulatory framework, the question of "efficiency" is managed by limiting the primary energy consumption and the $\mathrm{CO}_{2}$ emissions.

The first principle of thermodynamics states that the energy is conserved. Under this point of view, the heat (thermal energy) is equivalent to the work (mechanical energy). The first principle of thermodynamics does not distinguish between different forms of energy availability. The second principle of thermodynamics states that the energy is degraded. Under this point of view, the work (mechanical energy) is wholly convertible into heat (thermal energy), but not vice versa.

The second principle of thermodynamics distinguishes between different forms of energy availability, according to the possibility of converting into each other. A form of energy entirely convertible into another form of energy has high quality (e.g., mechanical energy). The quality of a form of energy decreases when decreases its ability to be converted into other forms of energy. As a result, the thermal energy at "high" temperature has a high quality, while the thermal energy at "low" temperature has a low quality.

The building first principle efficiency is calculated as the ratio between the useful effect and the energy expenditure. Starting from this calculation, it is possible to evaluate the quantity of the energy use. Instead, the second principle efficiency is calculated as the ratio between the thermodynamic potential input and the output ones. Starting from this calculation, it is possible to evaluate the quality of the energy use.

Once you define the energy needs for a given building, it is possible to use different energy sources to fuel it, obtaining the same overall first principle efficiency but different overall second principle efficiencies. Our definition of "building's energy impact on the environment" is based on the rational use of the available energy sources. The building energy assessment calculated using the primary energy or the $\mathrm{CO}_{2}$ emissions as parameters is not able to give a 
complete building energy impact evaluation. Therefore, we propose to include in the calculation even the exergy as a complementary parameter.

\subsection{Analysis of the Current Methods for the Building Energy Assessment}

The European Directives 2002/91/EC [1] and 2010/31/EU [2] of the European Parliament and of the Council establish the concept of "building energy performance" as the regulatory method for the building energy assessment. It is defined as the weighted energy amount, measured or calculated, necessary to meet the different building energy needs associated with a standard use of the building, which may include, inter alia, heating, domestic hot water, cooling, ventilation and lighting. The European Standard EN 15603 [8] defines the energy rating criteria based on the calculation of the weighted delivered and exported energy carriers for heating, cooling, ventilation, domestic hot water and lighting.

The calculation of the primary energy factors for the energy carriers, which should be exclusively based on technical and statistical considerations, is often subject to political decisions, also because an international shared calculation methodology lacks. So the energy policy is decisive for the results of the building energy assessment. The $\mathrm{CO}_{2}$ emission factors for the energy carriers define the amount of $\mathrm{CO}_{2}$ emitted into the atmosphere per unit of a given energy source. Their calculation is affected by the same problems that affect the primary energy factors calculation.

In summary, the current methods for the building energy assessment are a quantitative criterion related to the first principle. Through these methods, we obtain a partial and ineffective answer to the rational energy use issue. The appropriate use of the available energy sources is the key element in our definition of "building's energy impact on the environment".

\subsection{Problems of the Current Methods}

In the reference European scenario, the renewable energy sources will have an increasing important role. An on-grid building interacts bi-directionally with the energy supply chain. A building assessment based on primary energy or $\mathrm{CO}_{2}$ emissions is not sufficient to evaluate the appropriate use of the available energy sources.

We believe that the current methods for building energy assessment must be able to evaluate the building impact in terms of primary energy consumption and greenhouse gas emissions, as required from the European Union regulatory framework, but it should not neglect the energy sources' rational use. This aspect seems not enough guaranteed using the primary energy and/or $\mathrm{CO}_{2}$ emissions as building energy assessment parameter.

\section{Proposal for an Exergy Index}

\subsection{Exergy}

Exergy is the maximum theoretical work obtainable by definition from a certain amount of energy when it is brought in thermodynamic equilibrium with the reference environment. Work is a form of energy wholly convertible into any other form of energy. The exergy is defined as "theoretical", since it is assumed that, during the bringing in thermodynamic equilibrium, only reversible transformations are made.

Exergy is defined with respect to a reference environment. The reference environment constitutes the thermodynamic state in which a system is not able to do work. A system that is in a thermodynamic state different than the reference environment is able to do work. The exergy of a given quantity of energy varies with the reference environment and its properties, for which there is an absolute reading of energy interactions. The exergy is a useful concept because it extends the analysis of energy systems by a plan of the first principle to a plan of the second principle.

\subsection{Exergy Index}

According to our definition of "building's energy impact on the environment", a building energy 
assessment method must be able to evaluate the appropriate use of the available energy sources. The building designers should be able to design an efficient building on the basis of verifiable and measurable data.

Currently, the calculation results are dependent on the primary energy factors or $\mathrm{CO}_{2}$ emission factors. So the building designers have not an effective control on calculation results, because these parameters sometimes are not real or realistic.

The primary energy and the $\mathrm{CO}_{2}$ emissions indices are suitable to respectively evaluate the primary energy building impact and the $\mathrm{CO}_{2}$ emissions building impact. An exergy index also allows to evaluate the appropriate use of the available energy sources. This aspect seems not enough guaranteed using the primary energy or the $\mathrm{CO}_{2}$ emissions as building energy assessment parameter. The proposal of the exergy as a complementary parameter for the building energy assessment is a consequence of the final energy method limit, which fails to link the different energy carriers in one. We propose the exergy as a complementary parameter and not as an alternative strategy for building energy assessment.

Our proposal for an exergy index is not in conflict with the Directive 2010/31/EU [2], because it imposes the primary energy index use but it does not exclude the use of other indices. The proposed building energy assessment is composed by a double step: the first one is the evaluation of the energy consumption by the primary energy method and of the greenhouse gas emissions by the $\mathrm{CO}_{2}$ emissions method; the second one is the evaluation of the rational energy use by the exergy method. We underline that this second evaluation should be complementary compared to the first. It assesses the qualitative aspects related to thermodynamic potential and thus the energy potential degradation starting from the energy use.

The exergy method allows the designer to compare different energy design alternatives considering both the quantity and the quality of energy. Moreover, this method is free from coefficients extrinsic to the assessed building, like the energy supply chain efficiency and/or political strategy on the energy carriers, because the energy carriers are weighted only by thermodynamic parameters. So it allows an objective building overview and it leads to an effective comparison among different energy design alternatives.

The major benefits of the exergy index are the linking of the different energy carriers in one and the reaching of an objective and comparable result among different contexts.

The shared aspect between the energy and the exergy methods is the calculation methodology, based on the building energy needs reduction, particularly on the "useful thermal energy" reduction. The "useful thermal energy" is the energy required by a building for heating and cooling, determined as the sum of the energy and mass exchanges through the building envelope and the internal heat loads. This is the first step of the calculation methodology. The second one is to compare the different energy design alternatives for the given building, and to determine which is the energy source or energy carrier most appropriate to fuel its useful thermal energy.

The complementary use of different indices is due to the consideration that each of them is not able alone to completely assess the "building's energy impact on the environment".

\section{Test Cases}

A case study has been performed in order to show by a numerical example the topics discussed in Sections 2 and 3 of the paper. The aim is to make simple and intuitive understanding of the difference between energy and exergy assessment. The system analysis is not the sum of the individual analysis of every component that makes up the system, but it is an overall building assessment, summarized to one or more indexes.

The transient simulation software TRNSYS and some Excel sheets have been used for the building 
model. The building assessment results are given by the combination of the two modeling tools. The climate data have been taken from the test reference years available in the database of TRNSYS. The building geometric and thermophysical data, and the interactions between building and climate and between building and users, have been defined using the TRNBUILD application for TRNSYS and some hourly schedulers. Also, the air-conditioning system has been modeled and a relation has been established between the energy carriers that fuel it and the respective conversion factors in primary energy or emission factors in $\mathrm{CO}_{2}$. This relation is in compliance with the international standard EN 15603 [8].

The calculated indices are given by the ratio between the building primary energy consumption or the building $\mathrm{CO}_{2}$ emissions and the building floor area. The calculation period, in which the building assessment has been performed, is 1 year. The environment air surrounding the building has been taken as reference state for the exergy calculation, because it presents suitable thermodynamic features. The availability of hourly climate data has allowed to take into account the temperature hourly variation of the reference state. The exergy index, as the others indices, is referred to a $1 \mathrm{~m}^{2}$ of building floor area and to a 1 year of building use.

\subsection{Building Model}

The modeled building is a two floors, detached, residential building which has $210 \mathrm{~m}^{2}$ of floor area and $630 \mathrm{~m}^{3}$ of air-conditioned volume. The ratio between the external surface and the air-conditioned volume (shape factor) is 0.65 . The envelope thermal transmittance values are about $0.30 \mathrm{~W} / \mathrm{m}^{2} \mathrm{~K}$ for the opaque elements and about $2.00 \mathrm{~W} / \mathrm{m}^{2} \mathrm{~K}$ for the glazed elements. The glazing factor is about $15 \%$. The thermal energy need for air-conditioning has been calculated considering both energy and mass exchanges through the building envelope, including the solar incident radiation, and considering also the internal heat loads given by the users and appliances.

The heating and cooling plant is a conventional one, composed from radiant panels, zone regulation devices and distribution pipes. The features of the components and the components efficiency values have been kept constant for all the analyzed plant variants. The different component is the thermal production system, as explained in the following sections.

The purpose of the building model is to form a realistic and representative base in order to carry out specific considerations on energy carriers that fuel the air-conditioning system. The case study aim is to show the problems of the building assessment based on primary energy or $\mathrm{CO}_{2}$ emissions and the suitability of the building assessment based on exergy. Three different cases are showed in the following sections.

\subsection{Different Settings for Primary Energy Factors}

The first case performed shows the central role that the primary energy factors play for the building assessment results. We have compared two thermal production systems which fuel the heating plant. The first is fuelled by a gas boiler, having efficiency of 0.98 ; the second is fuelled by a wood boiler, having efficiency of 0.70 . In both variants, the building features are set identical. So the two systems produce the same amount of thermal energy.

We have found three different primary energy factors settings. The first establishes different values for each fuel, and distinguishes between a total factor and a non renewable factor. This setting is in compliance with the international standard EN 15603 [8]. The second, similar to that applied in Finland, establishes different values for each fuel, but not distinguishes between the total factor and the non renewable factor values. The third, similar to that applied in Sweden, establishes identical values for each fuel, considering only the total factor. The summary is shown in Table 1.

Fig. 1 shows the building energy assessment results using the three different criteria, considering only the 
primary energy consumption for heating.

Different primary energy factors settings lead to a very different building energy assessment results, at the same thermal energy required from the heating plant. Depending on the setting, the higher energy performance is given by the gas fuelled or by the wood fuelled thermal production system. Clearly, the assessment is not univocal. Moreover in some cases, the result is not representative of the building energy efficiency. At the same building energy efficiency, the thermal production system that requires the lowest amount of final energy is gas fuelled one. In some cases, it has the best energy performance, but in other cases the worst one.

So, the building exergy assessment result is univocal and constant as shown, compared to the different building energy assessment results. Instead of a choice among several primary energy factors settings, the fuels in input to the thermal production system are weighted depending on their low heating value. The low heating value of a fuel is a physical quantity dependent only on thermodynamic features.

\subsection{Solar Energy System}

The second case performed is about the renewable energy sources use. In particular, we refer to the solar energy conversion by photovoltaic solar panels. A BIPV (building integrated photo voltaic) system placed on the building roof has been modeled. The plant has $20 \mathrm{~m}^{2}$ of total surface, $0^{\circ}$ of azimuth angle and $15^{\circ}$ of tilt angle. The climate data are typical of the central Italy. The annual electric production of the BIPV system is $1,658 \mathrm{kWhe}$.

In this case, the building air-conditioning system is formed by an electric air heat pump which has 3.00 of SCOP (seasonal coefficient of performance), in heating, and 2.50 of SEER (seasonal energy efficiency ratio), in cooling. The control temperatures of the rooms are set to $20^{\circ} \mathrm{C}$ in winter and $26^{\circ} \mathrm{C}$ in summer. The activation period of the system depends on the specific climate profile. The photovoltaic system producibility is used to fuel the heat pump when there is an electricity demand, and when there is no energy request, it is sold to public dealer (grid).

According to the international standard EN 15603 [8], the solar energy incident on the photovoltaic panels should not be considered in the building energy balance. Therefore, we directly consider the electricity produced by the BIPV system in the building assessment. The partial and total values resulting from the calculation model are shown in Table 2.

The European average value of the primary energy factor for the grid electricity is 2.50 . For the primary energy calculation, we adopt the convention of assigning to the exported electricity, the same primary

Table 1 Different settings for primary energy factors.

\begin{tabular}{llllll}
\hline \multirow{2}{*}{ Setting } & \multicolumn{2}{c}{ Gas } & & \multicolumn{2}{c}{ Wood } \\
\cline { 2 - 3 } \cline { 5 - 6 } & Total & Non-renew & & Total & Non-renew \\
\hline EN 15603 & 1.36 & 1.36 & & 1.09 & 0.09 \\
Finland & 1 & 1 & & 0.5 & 0.5 \\
Sweden & 1.2 & - & & 1.2 & - \\
\hline
\end{tabular}

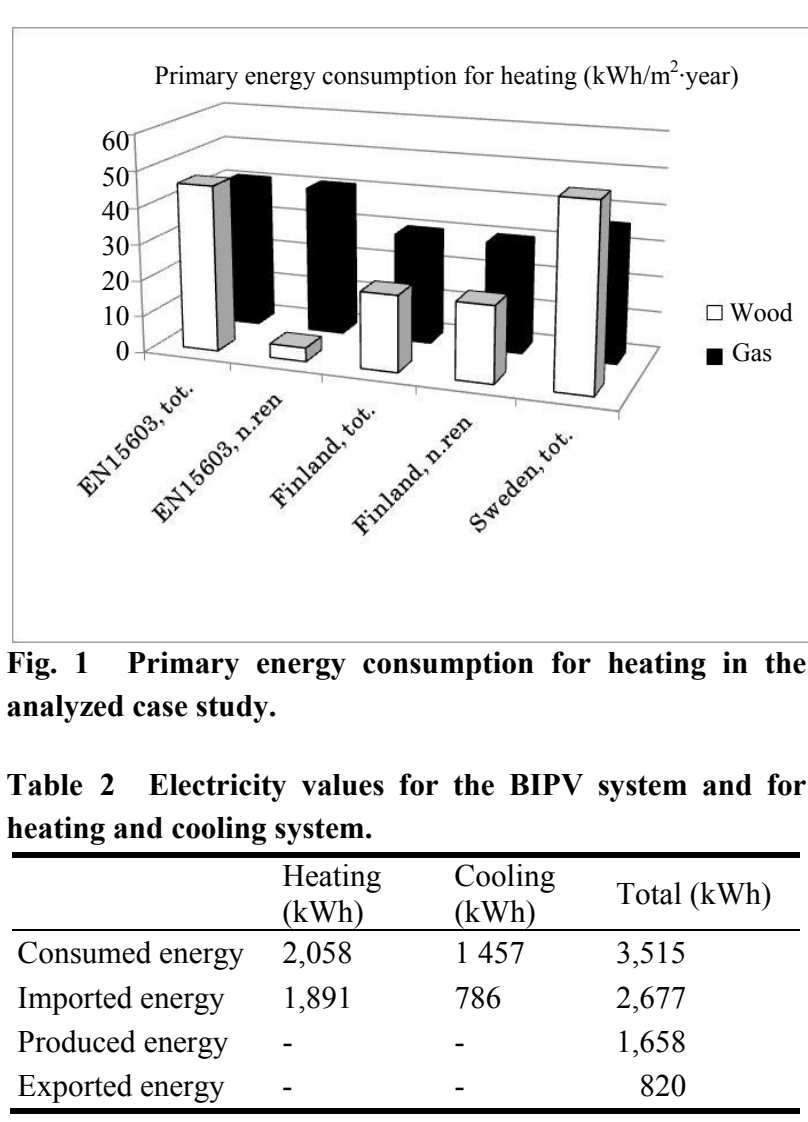


energy factor given to the imported electricity. This setting is common in the majority of the national regulations. The building primary energy consumption resulting for the performed case is $4,642 \mathrm{kWh}$. So the building energy performance is $22.0 \mathrm{kWh} /\left(\mathrm{m}^{2} \cdot\right.$ year $)$.

The same case has been performed using, for the cooling system, the same electric heat pump and, on the contrary, for the heating system, an electric boiler. The electric boiler has the efficiency of 1 . Moreover, the BIPV system placed on the building roof has been extended. The reached total area is $70 \mathrm{~m}^{2}$ and the annual electric production of the BIPV system is 5,803 $\mathrm{kWh}$. In this configuration, the building primary energy consumption is $4,570 \mathrm{kWh}$. So the building energy performance is $21.7 \mathrm{kWh} /\left(\mathrm{m}^{2} \cdot\right.$ year $)$, corresponding to the energy performance of the previous configuration.

Both cases have the same energy performance but different energy efficiency. In fact, in the first case, we use a heat pump with the efficiency of 3 , while in the second case, an electric boiler with the efficiency of 1 . On the contrary, the building exergy assessment result is representative of the building energy efficiency: in the first case, the exergy performance index is 16.73 $\mathrm{kWh} /\left(\mathrm{m}^{2} \cdot\right.$ year $)$; and in the second case, is 36.33 $\mathrm{kWh} /\left(\mathrm{m}^{2} \cdot\right.$ year $)$. It results that the configuration of the most efficient building has a better index than the one less efficient.

\subsection{Rational Energy Use}

The third case performed is about the rational resources use. Four different thermal production systems that fuel the building heating plant have been compared. The first is a gas boiler, the second is a hot water district heating, the third is an air electric heat pump, and the fourth is an electric boiler. To underline the difference between a energy and a exergy assessment, we show their seasonal average energy and exergy efficiencies in Table 3. They have been calculated on the building boundary. The heating system temperature is variable according to the environment air surrounding the building temperature. The district heating temperature is constant, equal to $90{ }^{\circ} \mathrm{C}$.

A comparative analysis of the four systems has been carried out. The calculation result, expressed as primary energy index and as exergy index, is shown on the previous graph (Fig. 2). The used conversion factors are taken from international standard EN 15603. We consider that the district heating is gas fuelled.

The building assessment results show that the purpose of the primary energy index is different from the one of the exergy index. According to this, we believe that the indices must be complementary and not alternative. The first has the purpose of establishing which building fuel modalities produce a lower consumption of primary energy resources. The second has the purpose of establishing which one among the available energy carriers on the building boundary allows to reduce the energy resources degradation.

Table 3 Seasonal energy and exergy efficiency for different thermal production systems.

\begin{tabular}{lll}
\hline Thermal production system & $\eta$ energy & $\eta$ exergy \\
\hline Gas boiler & 0.98 & 0.10 \\
District heating & 1.00 & 0.40 \\
Electric air heat pump & 3.00 & 0.28 \\
Electric boiler & 1.00 & 0.09 \\
\hline
\end{tabular}

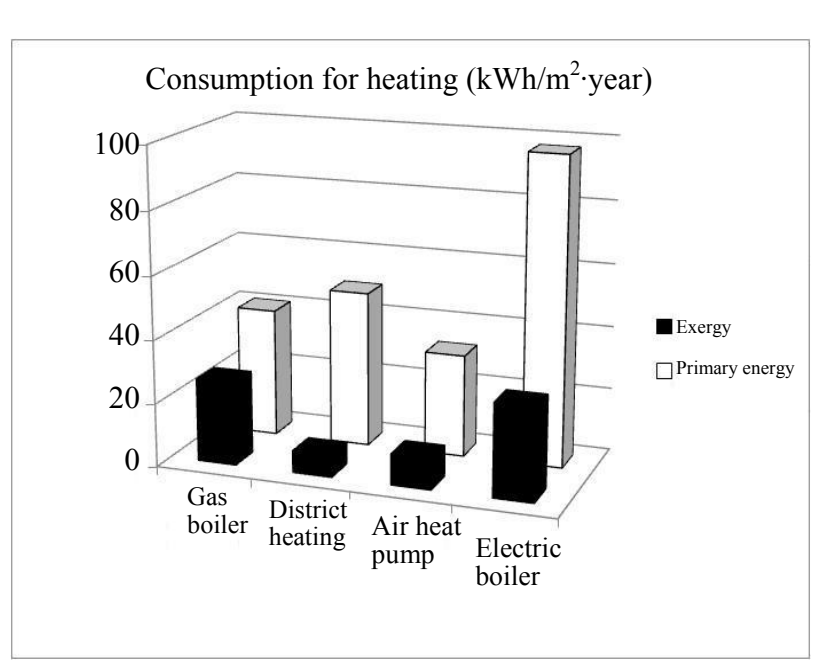

Fig. 2 Primary energy and exergy indices for different thermal production systems in the analyzed case study. 


\section{Conclusions}

Comparing the energy and the exergy index, we observe that the second one is able to solve some problems present in the first one. At the same time, the exergy index application as an assessment parameter allows a complete thermodynamic analysis of the building because it contemplates the energy carriers quality that crosses the system boundary and their degradation.

The described proposal establishes a base that gives a real answer to the demand of clarity and control of the calculation results, which are a relevant aspect especially for designers, and to the demand of stability and uniqueness of the results, which are a relevant aspect especially for the final users.

\section{References}

[1] European Parliament. 2002. Directive 2002/91/EC of the European Parliament and of the Council of 16 December 2002 on the Energy Performance of Buildings. European Parliament.

[2] European Parliament. 2010. Directive 2010/31/EU of the
European Parliament and of the Council of 19 May 2010 on the Energy Performance of Buildings (Recast). European Parliament.

[3] Yucer, C. T., and Hepbasli, A. 2011. "Thermodynamic Analysis of a Building Using Exergy Analysis Method." Energy and Buildings 43: 536-42.

[4] Zmeureanu, R. 2006. "Sustainable Buildings: Dream or Reality?." Journée Thématique SFT-IBPSA (Journal Thematic of French Thermal Society-International Building Performance Simulation Association) March: 1-8.

[5] IPCC (Intergovernmental Panel on Climate Change). 2014. Climate Change 2014-Synthesis Report. IPCC. Accessed January 1, 2015. http://www.ipcc.ch.

[6] Sharma, A., Saxena, A., Sethi, M., Shree, V., and Varun. "Life Cycle Assessment of Buildings: A Review." Renewable and Sustainable Energy Reviews 15 (1): 871-5.

[7] Xiao, F., and Wang, S. 2009. "Progress and Methodologies of Lifecycle Commissioning of HVAC (Heating, Ventilation and Air Conditioning) System to Enhance Building Sustainability." Renewable and Sustainable Energy Reviews 13: 1144-9.

[8] CEN (European Committee for Standardization). 2008. UNI (Enteltaliano di Unificazione) EN (Euro Norm) 15603, Energy Performance of Buildings-Overall Energy Use and Definition of Energy Rating. CEN. 